\title{
Climate Change Hastens Invasional Interference Between Two Notorious Invasive Plants, Common Ragweed (Ambrosia Artemisiifolia) and Redroot Pigweed (Amaranthus Retroflexus), in China
}

\author{
Cai-yun Zhao \\ CRAES: Chinese Research Academy of Environmental Sciences \\ Xiang-jian Zhao \\ CRAES: Chinese Research Academy of Environmental Sciences \\ Junsheng Li ( 106632752@qq.com) \\ CRAES: Chinese Research Academy of Environmental Sciences
}

\section{Research Article}

Keywords: elevated $\mathrm{CO} 2, \mathrm{~N}$ deposition, common ragweed, invasion, invasional interference, competitive ability

Posted Date: July 12th, 2021

DOI: https://doi.org/10.21203/rs.3.rs-521188/v1

License: @ (i) This work is licensed under a Creative Commons Attribution 4.0 International License. Read Full License 


\section{Abstract}

As multiple invaders co-occur in similar habitats, understanding the interactions between different invasive species is very important. Invasional meltdown and neutral and interference relationships have been reported. However, interspecific interactions may vary with environmental change due to the different responses of various invaders. To better understand the interaction of notorious invasive alien plants under global climate change, the growth characters of common ragweed (Ambrosia artemisiifolia) and redroot pigweed (Amaranthus retroflexus) were compared when they were planted in monoculture or mixed culture under four environmental treatments: elevated $\mathrm{CO}_{2}$, enriched $\mathrm{N}$, elevated $\mathrm{CO}_{2}+$ enriched $\mathrm{N}$ and a control. The results showed that 1) the plant height, basal stem diameter, and shoot, root, and total biomass of common ragweed all consistently increased in response to the treatments, while the growth traits of redroot pigweed were all inhibited. A significant $\mathrm{CO}_{2} \times \mathrm{N}$ interaction was found only for the shoot and total biomass of common ragweed. 2) Invasional interference between these two notorious alien invasive plants was discovered. Common ragweed consistently displayed an obvious competitive advantage over redroot pigweed regardless of treatment. 3) Elevated $\mathrm{CO}_{2}$ and enriched $\mathrm{N}$ obviously changed the seed mass frequency distribution of common ragweed: elevated $\mathrm{CO}_{2}$ increased the proportion of small seeds, while enriched $\mathrm{N}$ increased the proportion of large seeds. We conclude that common ragweed can outcompete redroot pigweed; moreover, elevated $\mathrm{CO}_{2}$ and $\mathrm{N}$ addition hasten this competitive advantage.

\section{Introduction}

Invasive plants often show high adaptability and phenotypic plasticity so that they can survive under altered environmental conditions (Davidson et al. 2011; Liu and van Kleunen 2017), but different invasive plants vary in their responses to environmental change, such as climate change (Dukes and Mooney 1999). Numerous case studies have demonstrated that invasive plants benefit from climate change (Dukes and Mooney 1999; Sorte et al. 2013; Liu et al. 2016; Mozdzer et al. 2016), especially $\mathrm{N}$ deposition and elevated $\mathrm{CO}_{2}$. Elevated $\mathrm{CO}_{2}$ can facilitate plant invasion by increasing plant photosynthesis, water use, growth rates, resource use efficiency, productivity, seed production and seed banks (Stewart and Potvin 1996; Smith et al. 2000; Weltzin et al. 2003; Ziska 2003; Dukes et al. 2011; Smith et al. 2013). N deposition can facilitate plant invasion by increasing $\mathrm{N}$ availability, plant-soil feedbacks, plant growth and competitive ability (Limpens et al. 2003; Zhang et al. 2010; He et al. 2011; Wan et al. 2019). In most research, these two factors are studied independently. Understanding how invasive plants respond to the interactive effect of elevated $\mathrm{CO}_{2}$ and $\mathrm{N}$ deposition is important but still underappreciated. Plant growth and biomass accumulation can be enhanced by elevated $\mathrm{CO}_{2}$, and the rates of these processes may be constrained by soil $\mathrm{N}$ availability (Luo et al. 2004 ; Feng et al. 2015). The invasion of Eupatorium adenophorum may be exacerbated by $\mathrm{CO}_{2}$ enrichment and $\mathrm{N}$ deposition (Lei et al. 2012).

Successful invasion by one plant not only is related to its adaptability to the environment but also depends on its ability to compete with other plants, including other invaders. As biological invasions increase in frequency, most habitats are invaded by multiple invasive plants, so interactions between different invasive species become more important (Shea and Chesson 2002). Invasive species can interact with each other (Russell et al. 2014; Kuebbing and Nunez 2014). One alien invasive species can be facilitated by another species, which is described as invasional meltdown (Simberloff and Von Holle 1999). Most known cases of invasional meltdown involve plants and organisms at other trophic levels, and there are few examples involving plant-plant interactions (Simberloff 2006). Invasion by one species can be negatively impacted by the presence of another invader, known as invasional interference (Yang et al. 2011; Rauschert and Shea 2012), especially when they require similar niches (Rauschert and Shea 2016). In some cases, these negative relationships may result in an invasive species replacing another invasive species, known as "overinvasion", which is used to describe this phenomenon in an animal context (Russell et al. 2014). Many authors have noted that a decline in one nonnative species results in a rapid increase in another, which indicates that competition among invasive plants may be common (Kuebbing and Nunez 2014). Invasional interference and overinvasion are understudied in plants. For example, the replacement of Spartina anglica by Spartina alterniflora was deduced (Zhi et al. 2007) in China. It is also possible that the interactions are neutral, as supported by a meta-analysis on the interactions of invasive animals (Jackson 2015).

The types of interactions among plants depend on environmental, species and individual features (Callaway and Walker, 1997). A series of studies have compared responses to climate change between invasive plants and native plants (Dukes and Mooney 1999; Liu et al. 2016) or naturalized alien plants and native plants (Sorte et al., 2013). However, different invasive plants are seldom compared in altered environments. Competitive ability varies with changes in environmental conditions; for example, an increased competitive advantage of invasive species has been attributed to higher $\mathrm{N}$ availability (Quinn et al., 2007). Variations in the environment can influence the intensity of competitive interactions (James and Richards 2007) and competitive relationships of plants because competing species respond differently to environmental change (Miller et al. 2007; Mamolos 2006). Moreover, competition relationships and elevated $\mathrm{CO}_{2}$ and $\mathrm{N}$ deposition often occur at the same time, and how these factors impact invasive species still needs to be determined.

To study the relationship of two notorious invasive plants, Ambrosia artemisiifolia (common ragweed) and Amaranthus retroflexus (redroot pigweed), and the impacts of elevated $\mathrm{CO}_{2}$ and $\mathrm{N}$ deposition on their relationship, we planted these two plants in monoculture and mixed culture under different environmental treatments, namely, elevated $\mathrm{CO}_{2}, \mathrm{~N}$ deposition, elevated $\mathrm{CO}_{2}+\mathrm{N}$ deposition and a control. The growth characters, biomass and relative yield of the two invasive species were all measured, and we also examined the seed production of common ragweed under competition and elevated $\mathrm{CO}_{2}$ and $\mathrm{N}$ deposition. We aimed to answer the following questions: (1) Do these two invasive alien plants respond to elevated $\mathrm{CO}_{2}, \mathrm{~N}$ deposition and competition in the same way? (2) Does climate change impact the relationship between two invasive alien plants? (3) How do elevated $\mathrm{CO}_{2}, \mathrm{~N}$ deposition and competition affect the reproduction of common ragweed?

\section{Materials And Methods Plant materials}


Two notorious invasive species were selected: Ambrosia artemisiifolia (common ragweed) and Amaranthus retroflexus (redroot pigweed), both of which are native to North America. Ambrosia artemisiifolia, which is an annual weed in crop fields, usually forms dense monospecific stands and produces a considerable amount of pollen (Gentili et al. 2018), and this weed is one of the most problematic aero-allergens (Ziska and Caulfield 2000). It was introduced into China in the 1930s and has since spread in twenty provinces (Liu et al. 2016). Amaranthus retroflexus occurs in various habitats, including agricultural and ruderal habitats (Valerio et al. 2011; Yang et al. 2011). It has a dramatic impact on ecosystems and native species (Rezaie and Yarnia 2009; Wang et al. 2017) and is regarded as the third most notorious weed in the world (Yang et al. 2011; Ma et al. 2012). Amaranthus retroflexus has expanded its distribution in large areas since its introduction to China in approximately 1905 (Qin et al. 2018). Seeds of common ragweed and redroot pigweed were collected from Mentougou District in Beijing (100 km from the experiment site) in October 2013.

\section{Experimental design}

The experiment was conducted in eight open-top chambers (OTCs: $2.2 \mathrm{~m}$ in height with an octagonal ground surface area of $6.25 \mathrm{~m}^{2}$ ) at the Experimental Base of the Chinese Research Academy of Environmental Sciences field laboratory located in Shunyi District, Beijing, China $\left(116.5875^{\circ} \mathrm{E}, 40.19^{\circ} \mathrm{N}\right)$, between

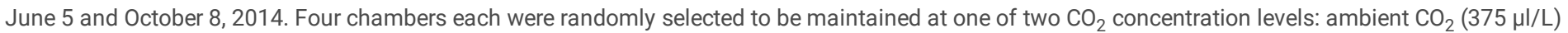
and elevated $\mathrm{CO}_{2}(700 \mu \mathrm{l} / \mathrm{L})$. Ten plastic pots $(32 \mathrm{~cm}$ in diameter and $38 \mathrm{~cm}$ in depth) were randomly arranged within each OTC in the following experimental design: $2 \mathrm{CO}_{2}$ levels $\times 2 \mathrm{~N}$ levels $\times 5$ competition levels $\times 4$ replicates. Thus, the experiment consisted of 80 pots in total. During the growing season, the total $\mathrm{N}$ addition levels were 0 and $0.80384 \mathrm{~g} \cdot \operatorname{pot}^{-1}\left(10 \mathrm{~g} \cdot \mathrm{m}^{-2} \times 0.080384 \mathrm{~m}^{2} \cdot \operatorname{pot}^{-1}\right)$. $\mathrm{N}$ was divided equally 8 times and uniformly applied in the form of $\mathrm{NH}_{4} \mathrm{NO}_{3}$ solution, and the control pots were sprayed with the same volume of water. Five competition levels were assigned as follows: $4 A: 0 A m$ (where $A$ and $A m$ denote common ragweed and redroot pigweed, respectively), $1 A: 3 A m, 2 A: 2 A m, 3 A: 1 A m$ and $0 A: 4 A m$. Four plants were planted in each plot under the different competition levels.

The seeds were treated at low temperature $\left(-20^{\circ} \mathrm{C}\right)$ for two months and then stored at room temperature in paper bags. The seeds of the two species were sown on May 7, 2014, at a depth of $2 \mathrm{~cm}$ in two field plots and then watered to field capacity once to stimulate germination. After three weeks, uniformly strong and tall seedlings were transplanted into pots in the OTCs according to the experimental design. To ensure homogeneity of the growing conditions, the pots were filled with a homogeneous mixture of local soil $(80 \%$; collected at depth of $3 \sim 15 \mathrm{~cm}$ from a weedy field neighboring the experiment base after the exclusion of topsoil) and vermiculite (20\%). Before transplantation, the following soil nutrient contents were measured: organic carbon, $8.4 \mathrm{~g} \cdot \mathrm{kg}^{-1}$; total $\mathrm{N}$, $0.73 \mathrm{~g} \cdot \mathrm{kg}^{-1}$; ammonium N, $10.77 \mathrm{mg} \cdot \mathrm{kg}^{-1}$; and nitrate $\mathrm{N}, 6.53 \mathrm{mg} \cdot \mathrm{kg}^{-1}$ - One week after transplantation, the elevated $\mathrm{CO}_{2}$ and $\mathrm{N}$ enrichment treatments were initiated. Pots were watered weekly as needed throughout the experiment. In each OTC, pots were moved randomly every month. In the elevated $\mathrm{CO}_{2}$ treatment,

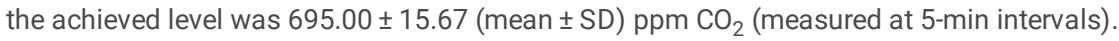

\section{Measurements and calculations}

The plant height, basal stem diameter and branch number per plant of common ragweed and redroot pigweed were measured. The shoots of each species in every pot were harvested from above the soil surface and stored in archival paper bags. Roots and soil were removed from the pots, and the roots of each species in every pot were collected and stored in archival paper bags. The shoots and roots were oven-dried at $80^{\circ} \mathrm{C}$ for $72 \mathrm{~h}$. The shoot biomass and the root biomass of each species in each pot were measured, and the total biomass of each species was calculated per pot.

Relative yield (RY) is a measure of the relative competitive abilities of two species. RY values $>1$ indicate that one species does better when competing against the other species than when competing against itself. High RY values indicate a high degree of competitiveness of one species relative to that of the other (Williams and McCarthy 2001). RY values are calculated using the equation below (Williams and McCarthy 2001; Weigelt and Jolliffe 2003).

$$
R Y_{i}=\frac{Y_{i j}}{p_{i} \times Y_{i}}
$$

where $\mathrm{Y}_{i j}$ is the yield of species $i$ in the presence of species $j, \mathrm{p}_{i}$ is the proportion at which species $i$ was sown, and $Y_{i}$ is the yield of species $i$ in monoculture under the same $\mathrm{CO}_{2}$ and $\mathrm{N}$ treatment as that for $\mathrm{Y}_{i j}$.

To analyze the impact of elevated $\mathrm{CO}_{2}$ and $\mathrm{N}$ addition on the reproduction of common ragweed, in each pot with common ragweed, seeds were collected by hand in October when the seeds were mature but had not yet begun to drop. The total seed number and the total seed weight were measured as seed yield. To examine the impacts of $\mathrm{CO}_{2}$ and $\mathrm{N}$ on the size of seeds of Ambrosia artemisiifolia, a total of 100 seeds were selected randomly from each pot of monocultured Ambrosia artemisiifolia; each seed was weighed and placed in one of four mass classes ( $<2 \mathrm{mg}, 2-5 \mathrm{mg}, 5-8 \mathrm{mg}$ and $>8 \mathrm{mg})$ on the basis of individual seed mass. The percent ratio of each class per pot was calculated, from which the seed mass frequency distributions were determined.

\section{Statistical analysis}

Three-way ANOVA was used to test the effects of $\mathrm{CO}_{2}, \mathrm{~N}$ and competition on the growth performance and competitive ability of Ambrosia artemisiifolia and Amaranthus retroflexus. When competition level had a significant effect, significant differences between competition levels were tested using the Tukey honesty significant difference post-hoc analyses (HSD) $(P<0.05)$. Two-way ANOVA was used to test the effects of $\mathrm{CO}_{2}$ and $\mathrm{N}$ on the seed size of $A m b r o s i a$ artemisiifolia. In all ANOVAs, data were log transformed where necessary to conform to the assumptions of normality and heteroscedasticity. All analyses were performed using IBM SPSS Statistics 19 (IBM, 2010).

\section{Results}




\section{Effects of $\mathrm{CO}_{2}, \mathrm{~N}$ and competition on the growth characters of two invasive alien plants}

The height, basal stem diameter and branch number of common ragweed were significantly increased by $\mathrm{N}$ addition when the species was grown in monoculture or with redroot pigweed, whereas only the height of redroot pigweed was increased by $\mathrm{N}$ addition (Fig. 1). Common ragweed benefitted more from the presence of redroot pigweed than vice versa. There were no distinct differences in height or basal stem diameter between the two alien plants when grown in monoculture; however, these characters were markedly decreased in redroot pigweed $(\mathrm{P}<0.001)$ and increased in common ragweed when these two species were grown together. The basal stem diameter of common ragweed in the $1 A: 3 A m$ competition treatment was larger than that in $3 A: 1 A m(P<0.001)$ and slightly larger than that in $2 A: 2 A m(P=0.02)$. Nonsignificant differences in the basal stem diameter of redroot pigweed were observed under different competition scenarios when the two alien plants were grown together. The branch number of common ragweed increased in response to competition ( $P<$ 0.001 ) and was not impacted by elevated $\mathrm{CO}_{2}$ and $\mathrm{N}$ addition (Table 1). No change in branch number of redroot pigweed in response to competition was observed, even in the monoculture treatment. The interaction effects of different factors did not affect the growth characters of the two invasive plants.

Table 1

Results of three-way ANOVA for the basal stem diameter, height and branch number of the alien invasive plants common ragweed and redroot pigweed according to $\mathrm{CO}_{2}, \mathrm{~N}$ and competition levels.

\begin{tabular}{|c|c|c|c|c|c|c|c|c|c|c|c|c|}
\hline & \multicolumn{5}{|c|}{ basal stem diameter } & \multicolumn{4}{|c|}{ height } & \multicolumn{3}{|c|}{ branch number } \\
\hline & \multirow{2}{*}{\multicolumn{3}{|c|}{$\begin{array}{l}\text { common } \\
\text { ragweed }\end{array}$}} & \multirow{2}{*}{\multicolumn{2}{|c|}{ redroot pigweed }} & \multirow{2}{*}{\multicolumn{3}{|c|}{ common ragweed }} & \multirow{2}{*}{$\begin{array}{l}\text { redroot } \\
\text { pigweed }\end{array}$} & \multirow{2}{*}{\multicolumn{2}{|c|}{ common ragweed }} & \multirow[t]{2}{*}{ redroot pigweed } \\
\hline & & & & & & & & & & & & \\
\hline Effect & df & $\mathrm{F}$ & $\mathrm{P}$ & $F$ & $\mathrm{P}$ & $\mathrm{F}$ & $\mathrm{P}$ & $\mathrm{F}$ & $\mathrm{P}$ & $\mathrm{F}$ & $\mathrm{P}$ & $P$ \\
\hline $\mathrm{CO}_{2}$ & 1 & 3.020 & 0.089 & 2.970 & 0.091 & 1.510 & 0.225 & 0.422 & 0.519 & 0.004 & 0.950 & -- \\
\hline$N$ & 1 & 33.395 & 0.000 & 3.707 & 0.060 & 16.006 & 0.000 & 21.267 & 0.000 & 0.076 & 0.784 & -- \\
\hline Competition & 3 & 15.213 & 0.000 & 26.352 & 0.000 & 1.998 & 0.127 & 20.343 & 0.000 & 15.496 & 0.000 & -- \\
\hline $\mathrm{CO}_{2} \times \mathrm{N}$ & 1 & 0.104 & 0.749 & 0.044 & 0.836 & 3.533 & 0.066 & 0.766 & 0.386 & 2.003 & 0.163 & -- \\
\hline $\mathrm{CO}_{2} \times$ Competition & 3 & 1.112 & 0.354 & 0.476 & 0.700 & 0.209 & 0.890 & 0.982 & 0.409 & 0.895 & 0.450 & -- \\
\hline $\mathrm{N} \times$ Competition & 3 & 1.182 & 0.326 & 1.429 & 0.246 & 0.412 & 0.745 & 0.748 & 0.529 & 2.174 & 0.103 & -- \\
\hline $\mathrm{CO}_{2} \times \mathrm{N} \times$ Competition & 3 & 0.130 & 0.942 & 0.232 & 0.874 & 0.834 & 0.482 & 0.244 & 0.865 & 1.082 & 0.366 & -- \\
\hline
\end{tabular}

\section{Effects of $\mathrm{CO}_{2}, \mathrm{~N}$ and competition on the biomass of the two invasive alien plants}

The three-way ANOVA results showed that $\mathrm{N}$ addition consistently resulted in significant increases in the shoot, root, and total biomass of common ragweed at all competition levels $(P<0.001)$ (Table 2; Fig. $2 A, B, C)$. Elevated $\mathrm{CO}_{2}$ increased the root biomass $(P=0.009)$ and the root-shoot ratio $(P=0.029)$ of common ragweed and inhibited the root biomass $(P=0.015)$ and the root-shoot ratio $(P=0.004)$ of redroot pigweed $(T a b l e ~ 2)$. An interaction effect of elevated $\mathrm{CO}_{2}$ and $N$ addition was observed for the shoot biomass $(P=0.035)$ and total biomass $(P=0.042)$ of common ragweed. Competition notably decreased the shoot biomass and total biomass of redroot pigweed $(\mathrm{P}<0.001)$ and differentially impacted the root biomass and the root-shoot ratio of these two invasive alien plants. The shoot biomass and total biomass of redroot pigweed under $3 A: 1 A m$ were lower than those under $1 A: 3 A m(\mathrm{P}<0.001), 2 A: 2 A m(\mathrm{P}<0.05)$ and monoculture $(\mathrm{P}<0.001)$. The root biomass of redroot pigweed under competition was lower than that under monoculture, with the root biomass under $3 A$ : $1 A m$ lower than that under $1 A: 3 A m(\mathrm{P}=0.006)$. The root-shoot ratio of redroot pigweed was significantly higher under monoculture than under $1 A: 3 A m(\mathrm{P}=0.03)$ and $3 A: 1 A m(P=0.016)$. The root biomass of common ragweed under $1 A: 3 A m$ was lower than that under $3 A: 1 A m(P=0.034)$ and monoculture $(P=0.001)$. The root-shoot ratio of common ragweed under $1 A: 3 A m$ was significantly lower than that under monoculture $(\mathrm{P}=0.011)$. 
Table 2

Results of three-way ANOVA for the shoot biomass, root biomass, root-shoot ratio and total biomass of two invasive alien plants according to $\mathrm{CO}_{2}$, I

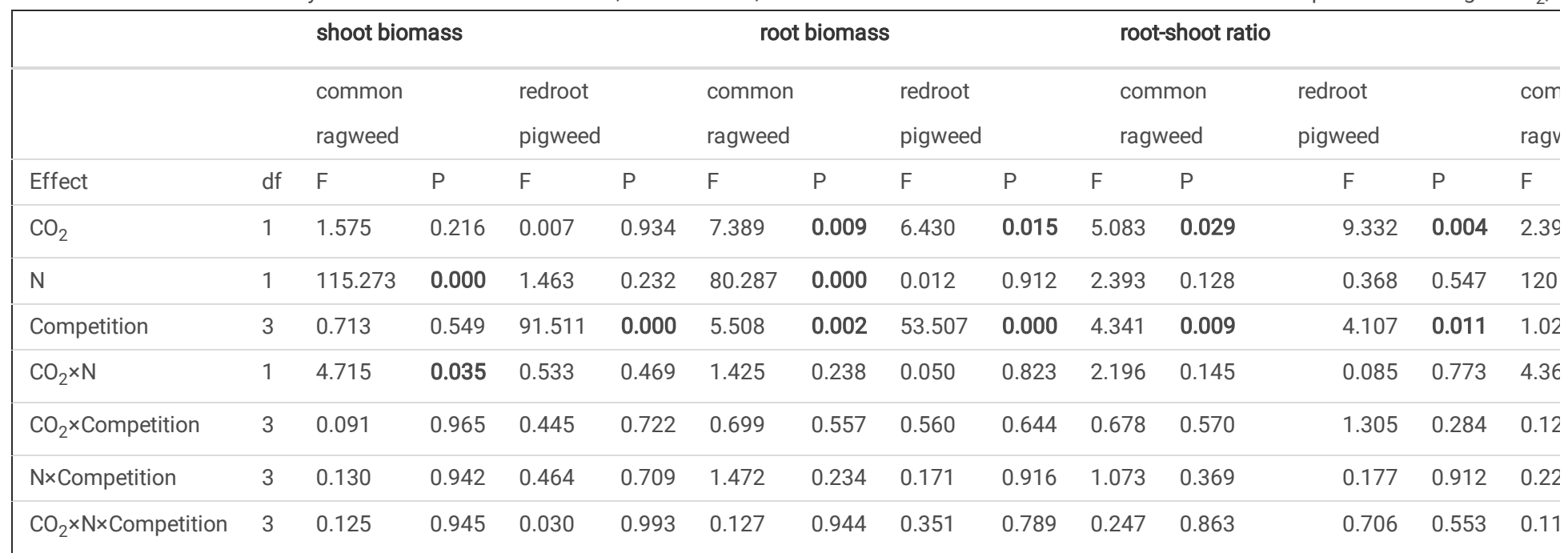

\section{Effects of $\mathrm{CO}_{2}, \mathrm{~N}$ and competition on the RY of two invasive alien plants}

The RY of common ragweed was higher than that of redroot pigweed, and the largest RY value of common ragweed reached 4.72; in contrast, the largest RY of redroot pigweed was only 0.87 . The RY of common ragweed was enhanced by elevated $\mathrm{CO}_{2}, \mathrm{~N}$ addition and competition (Table 3 ); moreover, the interactions of three factors and two factors also impacted the RY values of this invasive alien plant. By contrast, the RY values of redroot pigweed in all mixed cultures were significantly lower than expected. $\mathrm{CO}_{2}, \mathrm{~N}$ addition and competition all decreased the RY values of redroot pigweed, but the effect was significant only for $\mathrm{N}$ addition (Table 3, Fig. 3). These results showed that common ragweed had an obvious competitive advantage over redroot pigweed under control conditions; even one common ragweed plant could strongly inhibit three redroot pigweed plants.

Table 3

Results of three-way ANOVA for the relative yield of two invasive alien plants according to $\mathrm{CO}_{2}, \mathrm{~N}$ and competition levels.

\begin{tabular}{|c|c|c|c|c|c|}
\hline \multirow[b]{2}{*}{ Effect } & \multirow[b]{2}{*}{ df } & \multicolumn{2}{|c|}{ common ragweed } & \multicolumn{2}{|c|}{ redroot pigweed } \\
\hline & & $\mathrm{F}$ & $P$ & $\mathrm{~F}$ & $P$ \\
\hline $\mathrm{CO}_{2}$ & 1 & 8.201 & 0.007 & 1.184 & 0.284 \\
\hline $\mathrm{N}$ & 1 & 7.665 & 0.009 & 5.093 & 0.030 \\
\hline Competition & 2 & 11.594 & 0.000 & 0.625 & 0.541 \\
\hline $\mathrm{CO}_{2} \times \mathrm{N}$ & 1 & 7.980 & 0.008 & 1.593 & 0.215 \\
\hline $\mathrm{CO}_{2} \times$ Competition & 2 & 5.855 & 0.006 & 0.558 & 0.577 \\
\hline N×Competition & 2 & 5.905 & 0.006 & 1.540 & 0.228 \\
\hline $\mathrm{CO}_{2} \times \mathrm{N} \times$ Competition & 2 & 5.651 & 0.007 & 1.381 & 0.264 \\
\hline
\end{tabular}

\section{Effects of $\mathrm{CO}_{2}, \mathrm{~N}$ and competition on the reproductive characters of common ragweed}

$N$ addition increased the seed yield $(P<0.001$; Table 4; Fig. 4A) and decreased the seed mean weight $(P=0.003)$ of common ragweed. The seed number, seed total weight and seed mean weight were not significantly altered by elevated $\mathrm{CO}_{2}$, competition or their interaction. To examine the impacts of elevated $\mathrm{CO}_{2}$ and $\mathrm{N}$ addition, seeds collected from monoculture were grouped into four mass levels. The results showed that climate change obviously changed the seed mass frequency distributions. Elevated $\mathrm{N}$ and $\mathrm{CO}_{2}$ enhanced the degree of seed size variation, and higher proportions of larger seeds (mass $>8 \mathrm{mg}$ ) and smaller seeds (mass $<2 \mathrm{mg}$ ) were produced. Elevated $\mathrm{N}$ significantly increased the proportion of larger seeds from $3.29 \pm 1.12$ in the ambient $\mathrm{N}$ pots to $6.04 \pm 1.33$ in the enriched $N$ pots $(P<0.001 ;$ Fig. 5$)$ and decreased the proportion of smaller seeds from $3.34 \pm 1.24$ to $1.58 \pm 0.80(P=0.014 ;$ Table 3$)$. Elevated $\mathrm{CO}_{2}$ increased the proportion of smaller seeds to $12.53 \pm 5.64\left(\mathrm{P}=0.001\right.$; Fig. 5). There was no significant $\mathrm{N} \times \mathrm{CO}_{2}$ interaction effect on any of the abovementioned indices. 
Table 4

Results of three-way ANOVA for the seed number, seed total weight, and seed mean weight of common ragweed according to $\mathrm{CO}_{2}, \mathrm{~N}$ and competition levels.

\begin{tabular}{|llllllll|}
\hline & \multicolumn{6}{c}{ Seed number } & \multicolumn{3}{c|}{ Seed total weight } & \multicolumn{2}{l|}{ Seed mean weight } \\
\hline Effect & $\mathrm{df}$ & $\mathrm{F}$ & $\mathrm{P}$ & $\mathrm{F}$ & $\mathrm{P}$ & $\mathrm{F}$ & $\mathrm{P}$ \\
\hline $\mathrm{CO}_{2}$ & 1 & 0.281 & 0.598 & 1.319 & 0.256 & 0.145 & 0.705 \\
$\mathrm{~N}$ & 1 & 15.462 & 0.000 & 1.292 & 0.261 & 9.536 & 0.003 \\
\hline Competition & 3 & 2.416 & 0.078 & 2.222 & 0.098 & 0.276 & 0.842 \\
\hline $\mathrm{CO}_{2} \times \mathrm{N}$ & 1 & 1.726 & 0.195 & 1.040 & 0.313 & 0.001 & 0.976 \\
\hline $\mathrm{CO}_{2} \times$ Competition & 3 & 0.841 & 0.478 & 0.375 & 0.772 & 0.434 & 0.729 \\
\hline $\mathrm{N} \times$ Competition & 3 & 0.456 & 0.714 & 0.964 & 0.418 & 0.624 & 0.603 \\
\hline $\mathrm{CO}_{2} \times \mathrm{N} \times$ Competition & 3 & 1.255 & 0.300 & 1.017 & 0.393 & 1.346 & 0.271 \\
\hline
\end{tabular}

\section{Discussion}

\section{Negative interaction between common ragweed and redroot pigweed}

In this experiment, common ragweed was clearly the superior competitor under the different treatment levels, which implied a negative interaction between these two notorious alien invasive species. Negative relationships between alien invasive species are common at broader taxonomic levels, such as in insects (Braks et al, 2004), mammals (Bailey 1993; Russell et al. 2014) and plants (Williams and Buxton, 1995; Kuebbing and Nunez 2014). Competition between two alien invasive species can occur with one species limiting the material, substance, or space of the other when they live in the same habitat or require the same scarce resource (Belote and Weltzin 2006; Griffen et al. 2008). In most cases, the alien invasive species belong to the same genus; however, in some cases, they are phylogenetically dissimilar (Kuebbing and Nunez, 2014). For example, the removal of water hyacinth, which increased the invasion of alligator weed, indicated that competition can occur between phylogenetically dissimilar species (Wundrow et al., 2012). Thus, phylogenetic relatedness is not always necessary for predicting interactions between invaders (Cahill et al., 2008).

We focused on the relationship between two dissimilar invasive species that occupy similar niches. Common ragweed and redroot pigweed are both dominant invasive species included on the list published by the Ministry of Ecology and Environment of the People's Republic of China. The results of studies on interactions between invasive species are negative, which is not as commonly expected that a positive relationship will occur between dissimilar invasive species (Simberloff, 2006). These two invasive plants showed similar growth characters and biomass under monoculture (Figs. 1-2), but common ragweed showed a clear competition advantage in mixture culture (Figs. 1-3). The highest competitiveness was observed under $1 A$ : $3 A m$, where the RY of common ragweed increased to $350 \%$, while that of redroot pigweed decreased to $20 \%$. The growth characters of common ragweed, such as height and stem diameter, were also higher than those of redroot pigweed under interspecific competition, with the tall stature of the former species providing a strong advantage in the acquisition of light (Skálováet al. 2013). Rajcan et al. (2002) proved that both light quality and quantity influence the phenology of pigweed. The outcome of competition varies with the performance (Skálováet al. 2013) and resource availability (Lonsdale, 1999) of neighboring species. For example, Italian ryegrass has a competitive advantage over common ragweed (Leskovšek et al. 2012c), and redroot pigweed shows higher competitiveness than Phaseolus vulgaris $L$. (Amini et 2014). Competitiveness slightly decreased with an increasing density of common ragweed, which indicated inter- and intraspecific generality, as detected in other experiments (Kuebbing and Nunez 2014). Strong competitors often do better in the presence of interspecific competition than under intraspecific competition (Lambers et al. 2004; Golivets and Wallin 2018).

\section{Climate change hastens the negative interaction}

Alien species interactions will change in response to environmental alterations, such as climate change and $\mathrm{N}$ deposition (Tylianakis et al., 2008). Common ragweed benefited more than redroot pigweed from elevated $\mathrm{CO}_{2}$ and $\mathrm{N}$ addition, which resulted in the enhanced competitive ability of common ragweed.

$\mathrm{N}$ addition exerted a similar effect on the height of both common ragweed and redroot pigweed but contrasting effects on their biomass. We found that $\mathrm{N}$ addition increased the shoot, root and total biomass of common ragweed but had no impact on these characters in redroot pigweed (Fig. 2). The level of responsiveness differs considerably between species under $\mathrm{N}$ addition (Blackshaw et al. 2003). These results are consistent with the findings of Leskovšek et al. (2012b) that the height and dry matter of common ragweed were increased by $\mathrm{N}$ addition in both greenhouse and field experiments. $\mathrm{N}$ addition stimulated the height of redroot pigweed, which was also observed in other experiments (Wang et al. 2017), and no discernible effect on biomass was observed. Biomass allocation in response to nutrients was also different between the two invasive alien species. Compared with monoculture, $1 A: 3 A m$ and $2 A: 2 A m$ decreased biomass allocation to the roots in common ragweed, and $3 A$ :1 $A m$ increased it (Fig. 2). Results is dissimilar to previous study showed that biomass allocation of ragweed to the roots at $\mathrm{N}$ addition levels exhibited a low plasticity (Leskovšek et al, 2012a), and mainly because in our study inter- and intra- species competition are all considered. This result can be explained by resource-limitation theory, where plants allocate more biomass to roots in order to acquire more of the most limiting resource (Poorter and Nagel 2000; Liu et al. 2016). However, redroot pigweed allocated more biomass to the roots than to the shoots, as a clear decrease in shoot biomass and a slight decrease in root biomass were observed under competition (Fig. 2). The height disadvantage of redroot pigweed under competition results in a decrease in its light-capturing capacity (Wang et al., 2021), and root-foraging responses help it capture more nutrients (Keser et al. 2014, 2015). Decreased growth and physiological performance of redroot pigweed was also observed under competition (Wang et al. 2016). N addition 
increased relative competition intensity measured according to most traits of common ragweed but decreased that for most traits of redroot pigweed when the two species were grown together. The negative interaction of these two species was amplified by $\mathrm{N}$ addition.

Elevated $\mathrm{CO}_{2}$ increased the root biomass of common ragweed but decreased that of redroot pigweed. Most plants exhibit a positive growth response to elevated $\mathrm{CO}_{2}$ due to increased photosynthesis and/or nutrient use efficiency when other factors (e.g., water and nutrients) are not limited (Kimball et al. 2002). Some research has also indicated that elevated $\mathrm{CO}_{2}$ significantly increases shoot, root, and total plant biomass; plant height; and seed mass (Wayne et al. 2002; Rogers et al. 2006; Runion et al. 2014). Our results indicated that common ragweed gains a competitive advantage under $\mathrm{N}$ addition, so a positive relationship was observed between root biomass and elevated $\mathrm{CO}_{2}$. Otherwise, we speculate that there is an obvious limit of available $\mathrm{N}$ for redroot pigweed growth in the experimental area, and the $\mathrm{CO}_{2}$ effects on this weed are constrained by $\mathrm{N}$ limitation. We also observed that common ragweed grown in monoculture responded strongly to elevated $\mathrm{CO}_{2}$, and when grown under competition with redroot pigweed, it responded to elevated $\mathrm{CO}_{2}$ with a slight increase, whereas it exhibited a decrease under $1 \mathrm{~A}: 3 \mathrm{Am}$ of biomass. Invasive plant species show different responses to elevated $\mathrm{CO}_{2}$ under monoculture and under competition, as also demonstrated in Centaurea solstitialis (Dukes 2002). Although elevated $\mathrm{CO}_{2}$ often promotes invasion, it also commonly reduces $\mathrm{N}$ availability (Luo et al. 2004), which could indirectly limit $\mathrm{CO}_{2}$ effects on invasion (Sorte et al. 2013), especially under $\mathrm{N}$-limiting conditions such as those in our experiment. Blumenthal et al. (2016) also suggested that the lack of an elevated $\mathrm{CO}_{2}$ effect on Bromus tectorum may be due to indirect effects of $\mathrm{CO}_{2}$ on $\mathrm{N}$

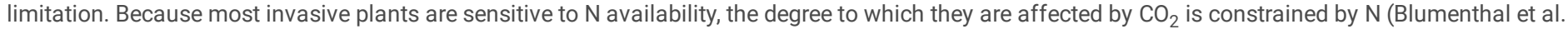
2016), and this constraint could be intensified by progressive N limitation (Luo et al. 2004) or alleviated by N deposition (Köchy and Wilson 2002; Fenn et al. 2003). Thus, we speculate that common ragweed invasion may be more serious than redroot pigweed invasion, as available $\mathrm{N}$ limitation is reduced by $\mathrm{N}$ deposition in our experimental area, whereas the positive effect of elevated $\mathrm{CO}_{2}$ will be greater for common ragweed.

\section{$\mathrm{N}$ addition enhanced the reproductive ability of common ragweed}

Effects of $\mathrm{CO}_{2}$ and $\mathrm{N}$ on the seed yield of common ragweed have been reported (Wayne et al. 2002; Leskovšek et al. 2012b). However, their effects on the frequency distribution of seed mass are unclear, although this trait is as important as seed yield. We found that elevated $\mathrm{CO}_{2}$ led to an increase in the proportion of smaller seeds; in contrast, $\mathrm{N}$ addition increased the proportion of larger seeds. Similarly, Hovenden et al. (2008) also found a higher frequency of small seeds of Austrodanthonia caespitosa under elevated $\mathrm{CO}_{2}$ compared with a control. Research on the effect of $\mathrm{N}$ deposition on seed mass frequency distributions is lacking. Further, $\mathrm{N}$ addition increased the number and decreased the mean mass of common ragweed seeds in our experiment, disagreeing with the lack of $\mathrm{N}$ effects on the seed number and seed yield of common ragweed reported in other research (Leskovšek et al. 2012b).

Seed size/mass is highly influential in determining seed germinability, seedling establishment and seedling growth, particularly in competitive environments (Stanton 1984; Moles and Westoby 2004; Souza and Fagundes 2014). Therefore, alterations in mean seed mass (Flynn et al. 2005) or seed mass frequency distributions (Hovenden et al. 2008) caused by global change are of substantial importance. Large seeds usually have a higher germination potential (Mandal et al. 2010), improve seedling growth (Stanton 1984; Mandal et al. 2010; Anis et al. 2014), facilitate the interspecific competitive ability of seedlings (Eriksson 1999), and enhance the tolerance of seedlings emerging from greater burial depths (Mandal et al. 2010). By contrast, small seeds consume fewer plant resources (Venable 1992) and generally disperse farther than large seeds (Cappuccino et al. 2002), which is an important life-history trait of invasive alien plants (Rejmanek and Richardson 1996). We speculate that more large seeds in common ragweed may improve its interspecific competitive ability through rapid seedling growth during the early phase, while more small seeds would be beneficial for farther dispersal. Therefore, the intensified seed size variation resulting from elevated $\mathrm{CO}_{2}$ and enriched $\mathrm{N}$ will promote the invasion of common ragweed. Of course, verifying this speculation will require more experiments to determine the exact relationships of seed size with seed germination, the seedling growth rate, interspecific competitive ability, and seed dispersal.

\section{Conclusion}

Common ragweed showed a higher competitive ability than redroot pigweed under interspecific competition, although no difference was observed under monoculture. The results revealed a negative interaction between these two notorious invasive species, which suggested invasional interference between them. In addition, elevated $\mathrm{CO}_{2}$ and $\mathrm{N}$ addition increased the competitive ability of common ragweed but suppressed that of redroot pigweed, and simulated $\mathrm{N}$ deposition had a stronger effect than $\mathrm{CO}_{2}$ on these two alien species. The results suggested that the competitive abilities of plants respond differently to climate change, $\mathrm{N}$ is a key factor in the invasion of these two species, and the role of elevated $\mathrm{CO}_{2}$ may be impacted by insufficient $\mathrm{N}$. Finally, $\mathrm{N}$ addition increased the proportion of smaller seeds of common ragweed, but elevated $\mathrm{CO}_{2}$ increased the proportion of smaller seeds; thus, $\mathrm{N}$ should be beneficial for reproduction, and $\mathrm{CO}_{2}$ favors the spread of common ragweed.

\section{Declarations}

\section{Acknowledgments}

We would like to thank all anonymous reviewers who helped improve the manuscript. This study was supported by the National Key Research and Development Program of China (2017YFC0506200 and 2016YFC1201100).

\section{Availability of data}

The data that supporting the results of this study can be accessed at https://figshare.com/s/4d7fb81abea5819e54c3.

\section{References}


1. Amini R, Alizadeh H, Yousefi A (2014) Interference between red kidneybean (Phaseolus vulgaris L.) cultivars and redroot pigweed (Amaranthus retroflexus L.). Eur J Agron 60:13-21

2. Anis M, Khan D, Zaki MJ, Khan MQ (2014) Seed mass variation and its effects of germination,seedling growth and the root infectivity with Macrophomina phaseolina in sunflower (Helianthus annuus L.). Head Neck 36:795-801.

3. Bailey EP (1993) Introduction of foxes to Alaskan Islands- history, effects on avifauna, and eradication. Resource Publication 193. U.S. Department of the Interior, Fish and Wildlife Service,Washington, D.C., USA.

4. Belote RT, Weltzin JF (2006) Interactions between two co-dominant, invasive plants in the understory of a temperate deciduous forest. Biological Invasions 8: 1629-1641.

5. Blackshaw RE, Brandt RN, Janzen HH, Entz T, Grant CA, Derksen DA (2003) Differential response of weed species to added nitrogen. Weed Science 51: 532-539.

6. Blumenthal DM, Kray JA, Ortmans W, Ziska LH, Pendall E (2016) Cheatgrass is favored by warming but not $\mathrm{CO}_{2}$ enrichment in a semi-arid grassland. Global Change Biol 22: 3026-3038.

7. Braks MAH, Honório NA, Lounibos LP, Lourenço-de-Oliveira R, Juliano SA (2004) Interspecific competition between two invasive species of container mosquitoes, Aedes aegypti and Aedes albopictus (Diptera: Culicidae), in Brazil. Annals of the Entomological Society of America 97(1):130-139.

8. Buczkowski G, Bertelsmeier C (2016) Invasive termites in a changing climate: A global perspective. Ecology and Evolution 7: $974-985$.

9. Cahill JF, Kembel SW, Lamb EG, Keddy PA (2008). Does phylogenetic relatedness influence the strength of competition among vascular plants? Perspect Plant Ecol Evol Syst 10: 41-50.

10. Callaway RM, Walker LR (1997) Competition and facilitation: A synthetic approach to interactions in plant communities.Ecology 78: $1958-1965$.

11. Cappuccino N, Mackay R, Eisner C (2002) Spread of the invasive alien vine Vincetoxicum rossicum: tradeoffs between seed dispersability and seed quality. Am Midl Nat 148: 263-270.

12. Davidson AM, Jennions M, Nicotra AB (2011) Do invasive species show higher phenotypic plasticity than native species and, if so, is it adaptive? A metaanalysis. Ecology Letters 14: 419-431.

13. Dukes JS, Chiariello NR, Loarie SR, Field CB (2011) Strong response of an invasive plant species (Centaurea solstitialis L.) to global environmental changes. Ecol Appl 21:1887-1894.

14. Dukes JS, Mooney HA (1999) Does global change increase the success of biological invaders?Trends in Ecology \& Evolution 14(4):135-139.

15. Dukes JS (2002) Comparison of the effect of elevated CO2 on an invasive species (Centaurea solstitialis) in monoculture and community settings. Plant Ecology 160: 225-234.

16. Eriksson $\mathrm{O}$ (1999) Seed size variation and its effect on germination and seedling performance in the clonal herb Convallaria majalis. Acta Oecol 20: 6166.

17. Feng Z, Pleijel H, Wallin G, Reich PB, Kammann Cl, Newton PC, Kobayashi K, Luo Y,Uddling J (2015) Constraints to nitrogen acquisition of terrestrial plants under elevated $\mathrm{CO}_{2}$. Global Change Biol 21: 3152-3168.

18. Fenn ME, Baron JS, Allen EB, Rueth HM, Nydick KR, Geiser L, Bowman WD, Sickman JO,Meixner T, Johnson DW (2003) Ecological effects of nitrogen deposition in the Western United States. Bioscience 53: 404-420.

19. Flynn DFB, Wolfe-Bellin K, Fang J, Bazzaz FA (2005) $\mathrm{CO}_{2}$ and nitrogen, but not population density, alter the size and $\mathrm{C} / \mathrm{N}$ ratio of Phytolacca americana seeds. Funct Ecol 19: 437-444.

20. Gentili R, Ambrosini R, Montagnani C, Caronni S, Citterio S (2018) Effects of soil pH on the growth, reproductive investment and pollen allergenicity of Ambrosia artemisiifolia L. Frontiers in Plant Science 9: 1335. doi:10.3389/fpls.2018.01335

21. Golivets M, Wallin KF (2018) Neihbour tolerance, not suppression, provides competitive advantage to non-native plants. Ecology Letter 1-15. doi:10.1111/ele.12934

22. Griffen BD, Guy T, Buck JC (2008) Inhibition between invasives: a newly introduced predator moderates the impacts of a previously established invasive predator. Journal of Animal Ecology 77: 32-40.

23. He WM, Yu GL, Sun ZK (2011) Nitrogen deposition enhances Bromus tectorum invasion: biogeographic differences in growth and competitive ability between China and North America. Ecography 34:1059-1066.

24. Hovenden MJ, Karene W, Rebeccae C, Jacquelinek VS, Amityl W, Yui O, Paulcd N (2008)Warming and elevated $\mathrm{CO}_{2}$ affect the relationship between seed mass, germinability and seedling growth in Austrodanthonia caespitosa, a dominant Australian grass. Global Change Biol 14:1633-1641.

25. Jackson MC (2015) Interations among multiple invasive animals. Ecology 96(8): 2035-2041.

26. James JJ, Richards JH (2007) Influence of temporal heterogeneity in nitrogen supply on competitive interactions in a desert shrub community. Oecologia 152: 721-727.

27. Keser LH, Dawson W, Song YB, Yu FH, Fischer M, Dong M, van Kleunen M (2014) Invasive clonal plant species have a greater root-foraging plasticity than non-invasive ones. Oecologia 174: 1055-1064.

28. Keser LH, Visser EJW, Dawson W, Song YB, Yu FH, Fischer M, Dong M, Van Kleunen M (2015) Herbaceous plant species invading natural areas tend to have stronger adaptive root foraging than other naturalized species. Frontiers in Plant Science 6: 273.

29. Kimball B A, Kobayashi K, Bindi M (2002) Responses of agricultural crops to free-air CO2 enrichment. Adv Agron 77: $293-368$.

30. Köchy M, Wilson SD (2002) Nitrogen deposition and forest expansion in the northern Great Plains. J Ecol 89: 807-817. 
31. Kuebbing S, Nunez MA (2014) Negative, neutral, and postitive interactions among nonnative plants: patterns, processes,and management inplications. Global change Biology 21(2): 926-934.

32. Lambers JHR, Harpole WS, Tilman D, Knops J, Reich PB (2004). Mechanisms responsible for the positive diversity-productivity relationship in Minnesota grasslands. Ecol Lett 7: 661-668.

33. Lei YB, Wang WB, Feng YL, Zheng YL, Gong HD (2012) Synergistic interactions of $\mathrm{CO}_{2}$ enrichment and nitrogen deposition promote growth and ecophysiological advantages of invading Eupatorium adenophorum in Southwest China. Planta 236:1205-1213.

34. Leskovšek R, Datta A, Knezevic SZ, Simončič A (2012a) Common ragweed (Ambrosia artemisiifolia) dry matter allocation and partitioning under different nitrogen and density levels. Weed Biol Manage 12: 98-108

35. Leskovšek R, Datta A, Simoncic A, Knezevic SZ (2012b) Influence of nitrogen and plant density on the growth and seed production of common ragweed (Ambrosia artemisiifolia L.). J Pest Sci 85: 527-539.

36. Leskovšek R, Eler K (2012c) The influence of nitrogen, water and competition on the vegetative and reproductive growth of common ragweed (Ambrosia artemisiifolia L.). Plant Ecol 213: 769-781.

37. Limpens J, Berendse F, Klees H (2003) N Deposition Affects N Availability in Interstitial Water, Growth of Sphagnum and Invasion of Vascular Plants in Bog Vegetation. New Phytol 157: 339-347.

38. Liu XY, Li JS, Zhao CY, et al. (2016) Prediction of potential suitable area of Ambrosia artemisiifolia L. in China based on MaxEnt and ArcGIS. Journal of Plant Proteciton, 43(6): 1041-1048.

39. Liu YJ and van Kleunen M. 2017. Responses of common and rare aliens and natives to nutrient availability and fluctuations. Journal of Ecology, 105: 1111-1122.

40. Liu YJ, Oduor AMO, Zhang Z, Manea A, Tooth IM, Leishman MR. Xu XL, van Kleunen M (2016)Do invasive alien plants benefit more from global environmental change than native plants? Global Change Biology 23(8): 3363-3370.

41. Lonsdale WM (1999) Global patterns of plant invasions and the concept of invasibility.Ecology 80:1522-1536.

42. Lu G, Wang J, Sang W (2012) Effects of nitrogen deposition on invasive and competitive abilities of an alien plant Ambrosia artemisiifolia. J Northeast For Univ 40: 60-66.

43. Luo Y, Bo SU, Currie WS, Dukes JS, Finzi A, Hartwig U, Hungate B, Murtrie REM, Oren R, Parton WJ (2004) Progressive nitrogen limitation of ecosystem responses to rising atmospheric Carbon dioxide. Bioscience 54: 731-739.

44. Ma JH, Xing GF, Yang WX, Ma LL, Gao M, Wang YG, HanYH (2012) Inhibitory effects of leachate from Eupatorium adenophorum on germination and growth of Amaranthus retroflexus and Chenopodium glaucum. Acta Ecol Sin 32: 50-56.

45. Mamolos AP (2006) Temporal differentiation in maximum biomass and nutrient accumulation rates in two coexisting annual plant species. J Arid Environ 64: 377-389.

46. Mandal SM, Chakraborty D, Gupta K (2010) Seed size variation: influence on germination and subsequent seedling performance in Hyptis suaveolens (Lamiaceae). Research Journal of Seed Science 3:185-192.

47. Miller AE, Bowman WD, Suding KN (2007) Plant uptake of inorganic and organic nitrogen: neighbor identity matters. Ecology 88: 1832-1840.

48. Moles AT, Westoby M (2004) Seedling survival and seed size: a synthesis of the literature.J Ecol 92:372-383.

49. Mozdzer TJ, Langley JA, Mueller P, Megonigal JP (2016) Deep rooting and global change facilitate spread of invasive grass. Biol Invasions 18: 26192631.

50. Poorter H, Nagel O (2000) The role of biomass allocation in the growth response of plants to different levels of light, CO2, nutrients and water: a quantitative review. Australian Journal of Plant Physiology 27: 595-607.

51. Qin Z, Zhang JE, Jiang YP, Wei H, Wang FG, Lu XN (2018) Invasion process and potential spread of Amaranthus retroflexus in China. Weed Res 58: 5767.

52. Quinn LD, Rauterkus MA, Holt JS (2007) Effects of nitrogen enrichment and competition on growth and spread of giant reed (Arundo donax). Weed Sci 55: 319-326.

53. Rajcan I, AghaAlikhani M, Swanton CJ, Tollenaar M (2002) Development of redroot pigweed is influenced by light spectral quality and quantity. Crop Sci 42: 1930-1936.

54. Rauschert ESJ, Shea K (2012) Invasional interference due to similar inter- and intraspecific competition between invaders may affect management. Ecol Appl 22: 1413-1420.

55. Rauschert ESJ, Shea K (2016) Competition between similar invasive species: modeling invasional interference across a landscape. The Society of Population Ecology 59(1): 79-88.

56. Rejmanek M, Richardson DM (1996) What attributes make some plant species more invasive?Ecology 77:1655-1661.

57. Rezaie F, Yarnia M (2009) Allelopathic effects of Chenopodium album, Amaranthus retroflexus and Cynodon dactylon on germination and growth of safflower. J. Food Agric.Environ. 7: 516-521.

58. Rogers CA, Wayne PM, Macklin EA, Muilenberg ML, Wagner CJ, Epstein PR, Bazzaz FA (2006)Interaction of the onset of spring and elevated atmospheric $\mathrm{CO}_{2}$ on ragweed (Ambrosia artemisiifolia L.) pollen production. Environ Health Perspect 114: 865

59. Runion GB, Prior SA, Price AJ, Mcelroy JS, Torbert HA (2014) Effects of elevated $\mathrm{CO}_{2}$ on biomass and fungi associated with two ecotypes of ragweed (Ambrosia artemisiifolia L.). Front Plant Sci 5: 1-7.

60. Russell JC, Sataruddin NS, Heard AD (2014) Over-invasion by functionally equivalent invasive species. Ecology 95(8): 2268-2276. 
61. Shea K, Chesson P (2002) Community ecology theory as a framework for biological invasions. Trends Ecol Evol 17:170-176.

62. Simberloff D (2006) Invasional meltdown 6 years later: important phenomenon, unfortunate metaphor, or both? Ecology Letters 9: $912-919$.

63. Simberloff D, Von Holle B (1999) Positive interactions of nonindigenous species: invasional meltdown? Biol Invasions 1: 21-32.

64. Skálová H, Jarošík V, Dvořáčková S, Pyšek P (2013) Effect of Intra- and Interspecific competition on the performance of native and invasive species of Impatiens under varying of shade and moisture. PlosOne 8(5): 1-3.

65. Smith SD, Charlet TN, Zitzer SF, Abella SR, Vanier CH, Huxman TE (2013) Long-term response of a Mojave Desert winter annual plant community to a whole-ecosystem atmospheric $\mathrm{CO}_{2}$ manipulation (FACE). Global Change Biol 20: 879-892.

66. Smith SD, Huxman TE, Zitzer SF, Charlet TN, Housman DC, Coleman JS, Fenstermaker LK,Seemann JR, Nowak RS (2000) Elevated CO 2 increases productivity and invasive species successin an arid ecosystem. Nature 408:79

67. Sorte CJB, Ibáñez I, Blumenthal DM, Molinari NA, Miller LP, Grosholz ED, Diez JM,D'Antonio CM, Olden JD, Jones SJ (2013) Poised to prosper? A crosssystem comparison of climate change effects on native and non-native species performance. Ecol Lett 16: 261-270

68. Souza ML, Fagundes M (2014) Seed size as key factor in germination and seedling development of Copaifera langsdorffii (Fabaceae). American Journal of Plant Sciences 05: 2566-2573.

69. Stanton ML (1984) Seed variation in wild radish: effect of seed size on components of seedling and adult fitness. Ecology 65:1105-1112.

70. Stewart J, Potvin C (1996) Effects of elevated $\mathrm{CO}_{2}$ on an artificial grassland community: competition, invasion and neighbourhood growth.Funct Ecol 10:157-166

71. Tylianakis JM, Didham RK, Bascompte J, Wardle DA (2008) Global change and species interactions in terrestrial ecosystems. Ecology Letters 11: 13511363.

72. Valerio M, Tomecek M, Lovelli S, Ziska L (2011) Quantifying the effect of drought on carbon dioxideinduced changes in competition between a C3 crop (tomato) and a C4 weed (Amaranthus retroflexus). Weed Res 51: 591-600.

73. Venable DL (1992) Size-number trade-offs and the variation of seed size with plant resource status. The American Naturalist 140: 287-304.

74. Wang CY, Zhou JW, Liu J, Jiang K (2017) Differences in funcitonal traits between invasive and native Amaranthus species under different forms of $\mathrm{N}$ deposition. Sci Nat104: 59-68.

75. Wang CY, Cheng HY, Wei M, Wang S, Wu BD, Du DL (2021) Plant height and leaf size:which one is more important in affecting the successful invasion of Solidago canadensis and Conyza canadensis in urban ecosystems? Urban Forstry \& Urban Greening https://doi.org/10.1016/j.ufug.2021.127033

76. Wan LY, Qi SS, Zou CB, Dai ZC, Ren GQ, Chen Q, Zhu B, Du DL (2019) Elevated nitrogen deposition may advance invasive weed, Solidago canadensis, in calcareous soil. Journal of Plant Ecology 12(5): 846-856.

77. Wayne P, Foster S, Connolly J, Bazzaz F, Epstein P (2002) Production of allergenic pollen by ragweed (Ambrosia artemisiifolia L.) is increased in $\mathrm{CO}_{2}$ enriched atmospheres. Ann Allergy, Asthma Immunol 8: 279-282.

78. Weigelt A, Jolliffe P (2003) Indices of plant competition. J Ecol 91: 707-720.

79. Weltzin JF, Belote RT, Sanders NJ (2003) Biological invaders in a greenhouse world:will elevated $\mathrm{CO}_{2}$ fuel plant invasions? Front Ecol Environ 1:146-153.

80. Williams AC, McCarthy BC (2001) A new index of interspecific competition for replacement and additive designs. Ecol Res 16: $29-40$.

81. Williams PA, Buxton RP (1995) Aspects of the ecology of two species of Passiflora (P. mollissima (Kunth) L. Bailey and P. pinnatistipula Cav.) as weeds in South Island, New Zealand. New Zealand Journal of Botany 33: 315-323.

82. Wundrow EJ, Carrillo J, Gabler CA, Horn KC, Siemann E (2012) Facilitation and Competition among Invasive Plants: A Field Experiment with Alligatorweed and Water Hyacinth. PLoS ONE 7(10): e48444. doi:10.1371/journal.pone.0048444

83. Yang Y, Zhao WJ, Li ZH, Zhu SF (2011) Molecular identification of a "Candidatus Phytoplasma ziziphi"-related strain infecting Amaranth (Amaranthus retroflexus L.) in China. J. Phytopathol. 159: 635-637.

84. Zhang Y, Ding W, Cai Z, Valerie P, Han F (2010) Response of methane emission to invasion of Spartina alterniflora and exogenous N deposition in the coastal salt marsh. Atmos Environ 44: 4588-4594.

85. Zhi YB, Li HL, An SQ, Zhao L, Zhou CF, Deng ZF (2007) Inter-specific competition: Spartina alterniflora is replacing Spartina anglica in castal China. Estuarine Costal and Shelf Science 74: 437-448.

86. Ziska LH (2003) Evaluation of the growth response of six invasive species to past,present and future atmospheric carbon dioxide. J Exp Bot 54:395-404

87. Ziska LH, Caulfield FA (2000) Rising $\mathrm{CO}_{2}$ and pollen production of common ragweed (Ambrosia artemisiifolia), a known allergy-inducing species: implications for public health. Funct Plant Biol 27: 893-898.

\section{Figures}




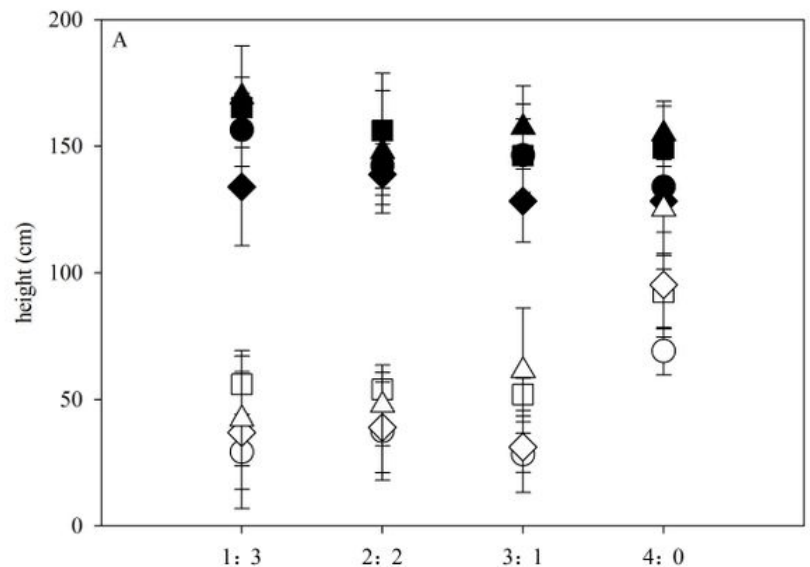

competition levels

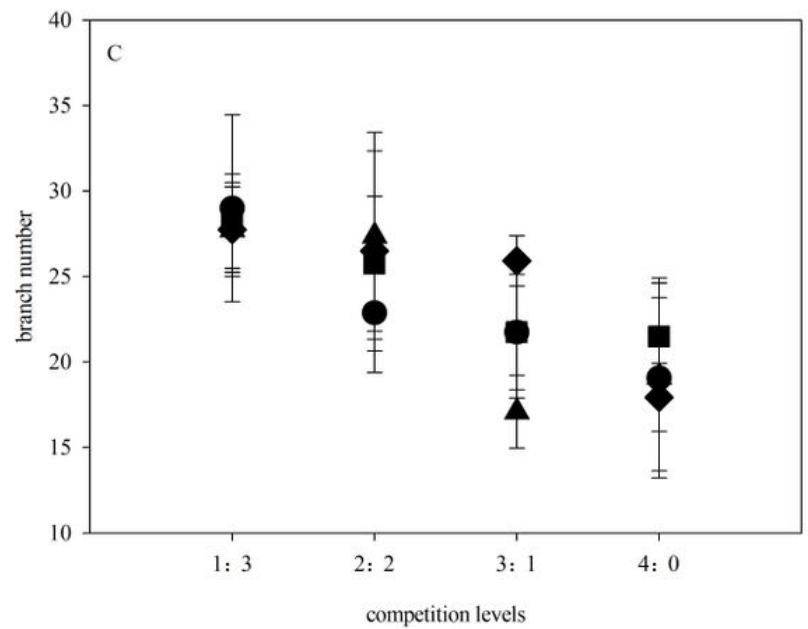

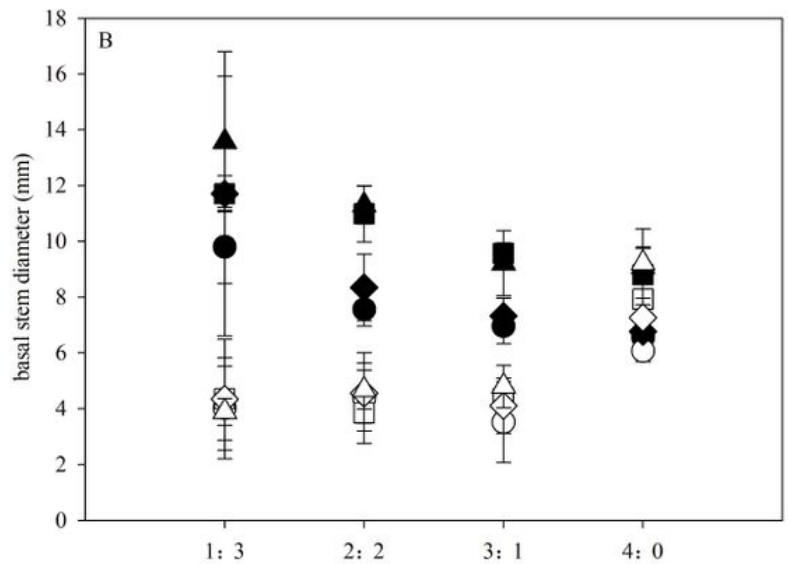

competition levels

CK-common ragweed CK-redroot pigweed

- eN-common ragweed

eN-redroot pigweed

- $\mathrm{eCO}_{2}$-common ragweed

$\diamond \mathrm{eCO}_{2}$-redroot pigweed

- eNe $+\mathrm{CO}_{2}$-common ragweed

$\triangle \mathrm{eN}+\mathrm{eCO}_{2}$-redroot ragweed

\section{Figure 1}

Effects of elevated $\mathrm{CO} 2, \mathrm{~N}$ addition and competition level on the growth characters of two invasive alien plants. A. Height. B. Basal stem diameter. C. Branch number. On the horizontal axis, 1:3 refers to one common ragweed plant and three redroot pigweed plants, 2:2 refers to two common ragweed plants and two redroot pigweed plants, 3:1 refers to three common ragweed plants and one redroot pigweed plant, and 4:0 refers to four common ragweed plants or four redroot pigweed plants. 

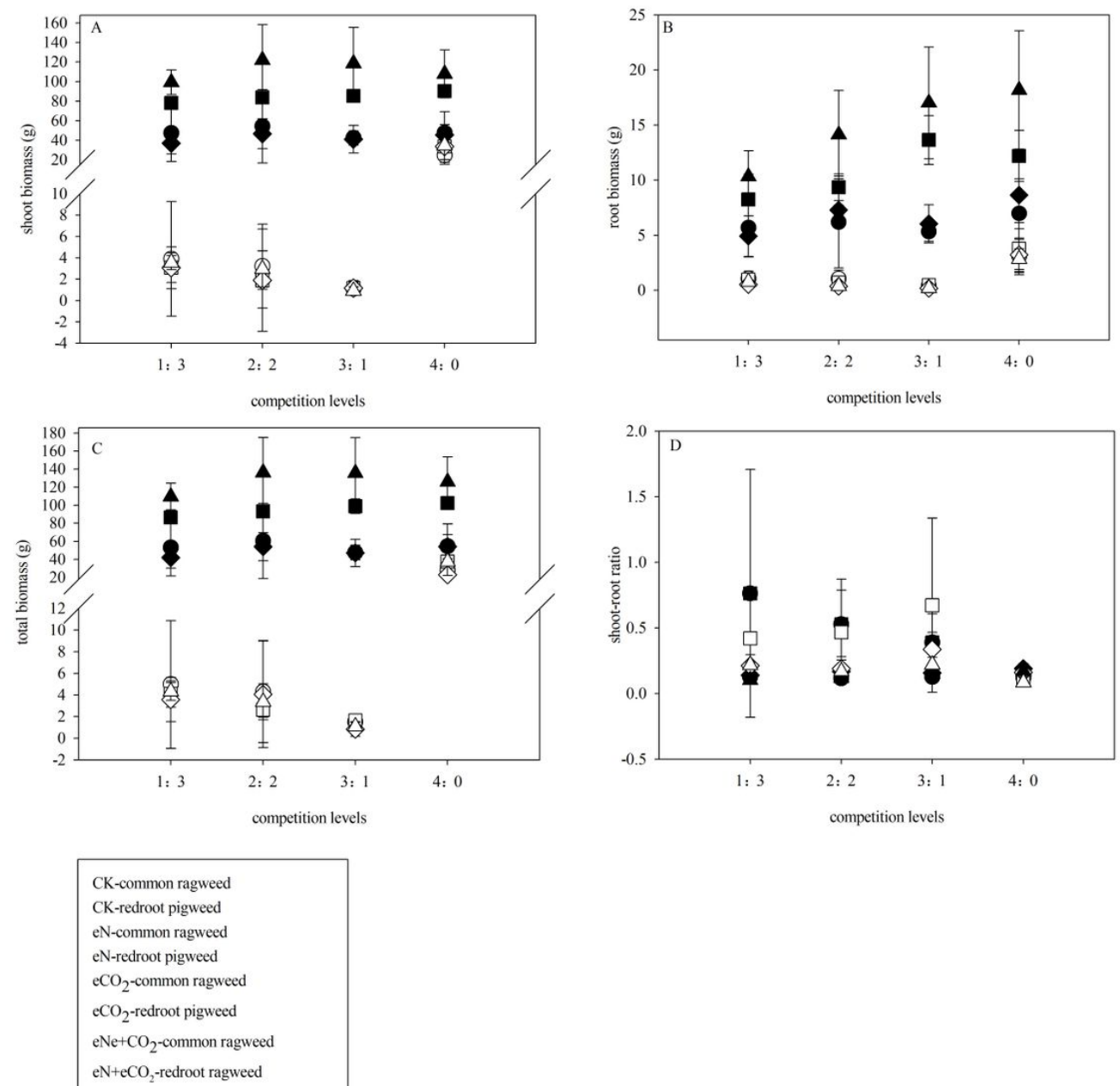

\section{Figure 2}

Effects of $\mathrm{CO} 2, \mathrm{~N}$ and competition levels on the biomass of two invasive alien plants. A. Shoot biomass. B. Root biomass. C. Total biomass. D. Root-shoot ratio. On the horizontal axis, 1:3 refers to one common ragweed plant and three redroot pigweed plants, 2:2 refers to two common ragweed plants and two redroot pigweed plants, 3:1 refers to three common ragweed plants and one redroot pigweed plant, and 4:0 refers to four common ragweed plants or four redroot pigweed plants. 


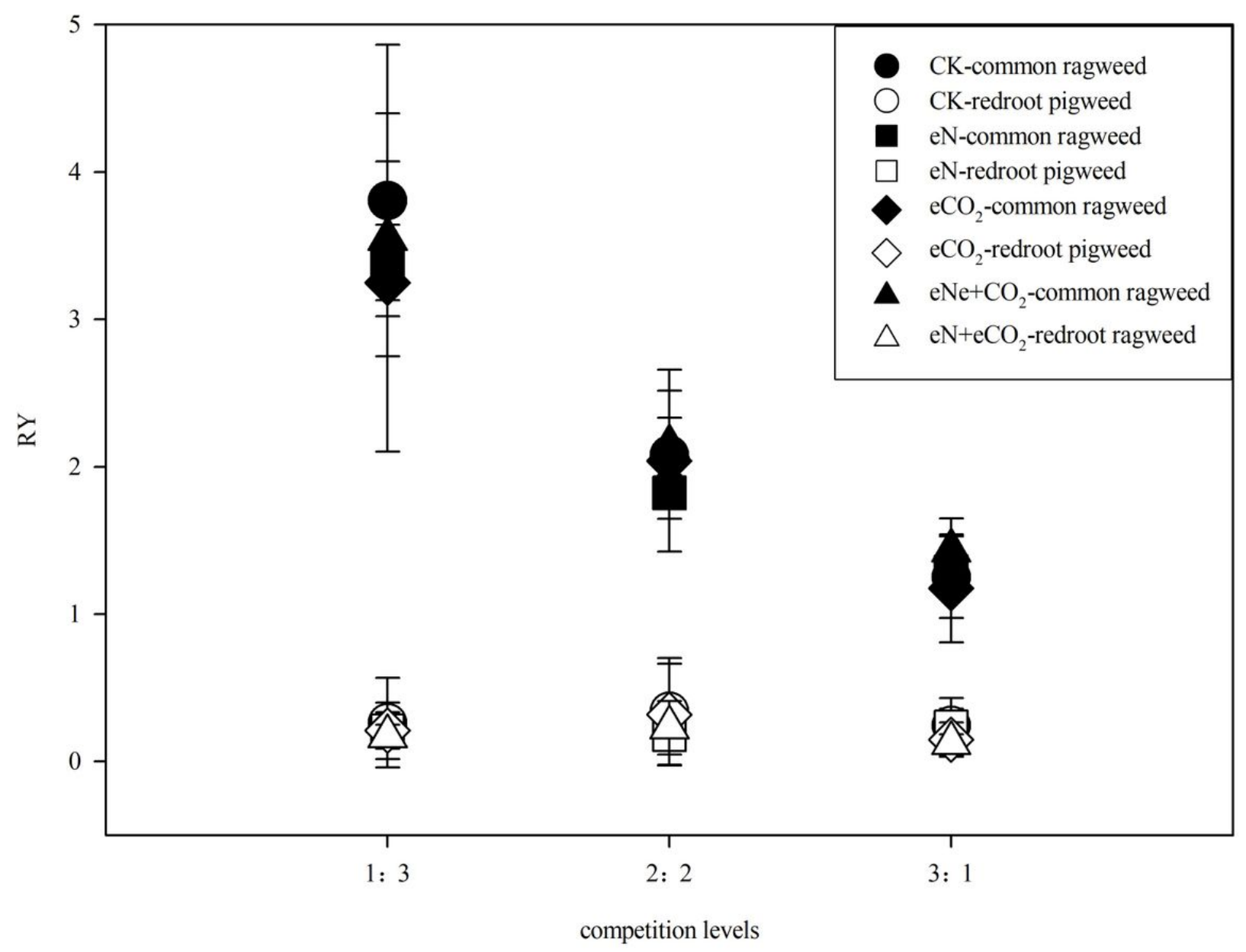

Figure 3

Effects of elevated $\mathrm{CO} 2, \mathrm{~N}$ addition and competition level on the RY of two invasive alien plants. 

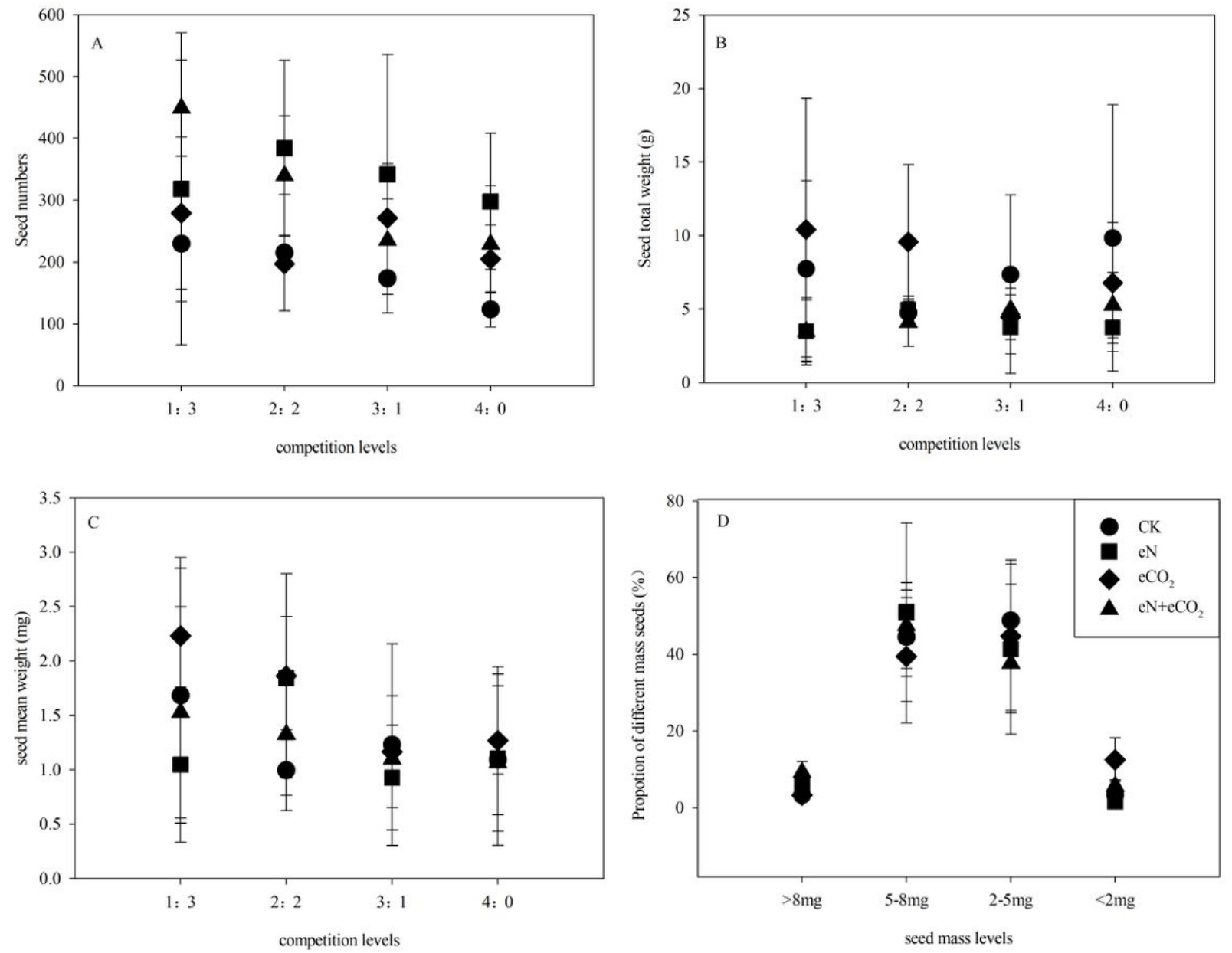

Figure 4

Effects of elevated $\mathrm{CO} 2, \mathrm{~N}$ addition and competition level on the reproductive characters of common ragweed. A. Seed number. B. Seed total weight. C. Seed mean weight. On the horizontal axis in A-C, 1:3 refers to one common ragweed plant and three redroot pigweed plants, 2:2 refers to two common ragweed plants and two redroot pigweed plants, 3:1 refers to three common ragweed plants and one redroot pigweed plant, and 4:0 refers to four common ragweed plants. D. Proportions of different seed masses. The horizontal axis in D shows the different seed mass levels.

\section{Image not available with this version}

\section{Figure 5}

Figure 5 